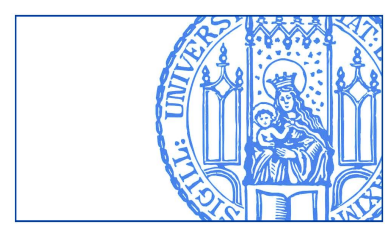

Schlicht, Ekkehart:

Patterned Variation: The Role of Psychological Dispositions in Social and Institutional Evolution

Munich Discussion Paper No. 2021-1

Department of Economics

University of Munich

Volkswirtschaftliche Fakultät

Ludwig-Maximilians-Universitäł München

Online at https://doi.org/10.5282/ubm/epub.76567 


\title{
Patterned Variation: The Role of Psychological Dispositions in Social and Institutional Evolution
}

by

\author{
EKKEHART SCHLICHT*
}

\section{Introduction}

The new institutional economics has one of its roots in evolutionary thinking. ${ }^{1}$ The idea is that there is competition among organizational forms. Some forms spread faster than others and thereby displace and eventually destroy the less well adapted forms. In the end, the most "efficient" organizational formation will survive, where "efficiency" is a social analogue for biological fitness. The process is predominately envisaged as a process of what I am going to term "blind evolution:" a combination of random variation and selection. ${ }^{2}$

One task of these remarks is to put into question the idea that it is indeed random variation which drives evolutionary processes. It will be proposed that this idea of random variation is of rather limited value for the purposes of social analysis. If evolution is to be able to work successfully on complex organisms or organizations, it is necessary that variation occurs in a patterned fashion with systematically correlated changes. ${ }^{3}$

Once the importance of patterned variation is established, it must be asked where the patterns come from. It will be argued that, for the purpose of the social sciences, these patterns are generated by psychological regularities, both cognitive and emotional.

The argument about patterned variation will be presented in the next three sections. Sections 5 to 7 illustrate patterning processes in biological evolution, social evolution, and learning. These processes exhibit surprising parallels. The

- I thank Knut Borchardt, Ariane Breitfelder, Andreas Gösele, Dieter Grimm, Gisela Kubon-Gilke, Erik Leyers, Brian Loasby, Florian Mayer-Haßelwander, Peter Mücke, Uwe Mummert, and Andreas Nicolin for helpful comments on an earlier draft.

1 AlChian [1950].

2 I use the term "blind evolution" in analogy to CAMPBELL's [1974, 421] "blind variation and selective retention."

3 Related views, as pertaining to the social sciences, may be found in HaLlPIKE [1986, $81-145]$ and KuBON-GILKE [1997, 470-478]. 
subsequent sections elaborate on the nature of social and institutional evolution, as conceived from the psychological perspective outlined in the paper.

\section{Two Types of Evolution}

In order to set the stage for the argument, two types of change may be contrasted. They will be termed "blind evolution" and "organic evolution," respectively.

Blind Evolution. A predominant view of evolution, frequently invoked in institutional economics, is as follows. Evolution occurs by the joint action of random variation and survival of the fittest. This idea is applied to explaining not only the evolution of biological species, but also the evolution of human societies. It has even been applied to psychology, where behaviorists have depicted individuals as emitting random behaviors that are then selected by the environment.

In institutional economics, institutions are explained by random variation and competitive selection. There is institutional variation, which may come about for various reasons. Personal preferences, coincidences, idiosyncratic convictions of some individuals, or even superstitious beliefs may entail such institutional variation. Many variations will fail and disappear, but occasionally a variant may be generated that is able to survive and spread by outcompeting other institutional solutions. In this way, new institutions may come into being.

Organic Evolution. Another vision of the evolutionary process emphasizes the internal tendencies, regularities, and constraints which govern the growth of an organism or institution, or the way it responds to new exigencies. The most prominent example of this organic evolution (as it may be termed) is the development of the system of law. In law, new cases are treated in analogy to old cases, and inconsistencies in the body of the law are removed by refining definitions, classifications, and delineations. If changing circumstances require changes in the law, these changes are introduced so as to conform with the principles underlying the body of the law as a whole, which constrains possible changes. Ideally, such processes are driven by legal reasoning alone. The actual process of the evolution of law is, however, not exclusively propelled by pure reason, but is subjected to quite mundane and often quite distorting interests of interfering parties.

Other cases of organic evolution are even more extreme in their reliance on organic rule-guided growth. Some branches in pure mathematics seem to evolve entirely on their own, driven by their internal logic. This is not to say that selection processes do not play any role; rather the selection processes themselves reflect both the internal logic of mathematics and the social pressures prevailing within the mathematical community. The referees of mathematical journals decide on publication by following such reasons, and the appointments 
to professorships are influenced by similar considerations. It seems, however, entirely misleading to describe the growth of mathematics as governed by the two unrelated elements of random variation and competitive selection. Rather, the logic of mathematics guides the generation, the evaluation, and the selection of new results.

In drawing a distinction between blind and organic evolution, I do not want to suggest that the received arguments in institutional and evolutionary economics fit nicely into the one or the other category. My purpose is rather to draw attention to an important distinction and to some arguments surrounding this distinction which may help to sharpen our ideas about social and institutional evolution. These issues are typically left unmentioned. HAYEK [1945, 528] simply says, for instance, that man had "stumbled" upon the price system without understanding it. Other writers, such as ALCHIAN [1950] with his "chance" model, stress the blind elements in evolution quite explicitly. Still others, such as LIST [1837] and MARSHALL [1890/1920], allude more to organic patterns, but these arguments are presented in an ad-hoc fashion in the context of discussing specific problems. ${ }^{4}$ My purpose is to face the general issue head on.

\section{Fitness Landscapes}

It will be argued in the following that blind evolution is not a useful mechanism for generating change in complex organisms or institutions, and that variation must be organic (in the sense outlined above) in order to produce change in any relevant sense. Blind evolution can only serve to locally adapt in a small way.

The major obstacle posted to blind evolution is well illustrated by the following example from engineering. With the advent of the computer arose the possibility of using the mechanism of random variation and selection for optimizing computer programs. The attempt was made. Certain computer programs - simple programs by current standards - were subjected to random disturbances in their code. It was hoped that among the many failures and crashes to be expected, some variants with improved performance would emerge. This was, however, not the case. There was no way to improve a computer program in this manner. The attempt was a complete failure. ${ }^{5}$

The reason for this failure is straightforward. A computer program may be described as a sequence of digits of a certain length. Consider all conceivable sequences of digits of equal length. This set describes all possible computer programs of given length. The "fitness" of one particular program may be measured by the speed it needs for performing the required operation. Each

4 For a variety of usages of "evolutionary economics" see HodGSON [1996].

5 EDEN [1967, 11]. The argument carries over to biological organisms where - even for the genom of a simple bacterium - the age of the world would not have been sufficient to generate the appropriate gene frequencies randomly (KüPPERS [1983]). 
member of the set of programs may thus be characterized by a certain fitness. In the case of computer programs, the "fitness landscape" covering the plane of possible programs has a very jagged profile. ${ }^{6}$ Nearly all programs have zero fitness. The plane is sprinkled sparsely with a few isolated pinnacles characterizing the positive fitness of workable programs.

Blind evolution cannot work on such a jagged fitness profile. It works best on smooth fitness surfaces with bell-shaped hills. Blind evolution can easily find the path of steepest ascent and reach the point of maximum fitness quickly under such circumstances. Rolling fitness landscapes of this kind must implicitly be presupposed in all models which employ ideas about blind evolution or adaptive learning.

Complex organisms or organizations are, however, characterized by functionally correlated traits. Changing one attribute without simultaneously changing some others in a certain way is doomed to failure. A larger organism requires a larger respiratory system, for instance, or a change of one trait in a computer program requires a correlated change in other traits so that the program remains functional. ${ }^{7}$ In terms of fitness landscapes, correlated traits induce ridges and canyons. Evolution in such ridged landscapes requires strategies other than blind trial-and-error in order to succeed. In particular, variation must be kept within certain limits and must not occur randomly, but in a correlated fashion. ${ }^{8}$

\section{Patterned Variation}

For complex organisms, blind evolution is therefore not a feasible mechanism for improvement and adaptation. Because random variation cannot produce evolution of complex organisms, variation must be structured and patterned. Biologists have speculated that such patterned variation is itself the outcome of evolutionary processes, and have established theoretically and experimentally that patterned variation will occur as a result of selection processes. Those genes which generate a good pattern must be expected to outcompete others. ${ }^{9}$

"Biologists use the twin concepts of "adaptive landscapes" and "fitness landscapes" (see, e.g., ElDREGDE [1989, 19ff.]).

7 WAGNER [1984a] argues that these problems become important if more than three independent characters contribute to the variation of a functionally constrained system.

8 Accordingly, the evolutionary strategy for optimizing technical systems, as initiated by RECHENBERG [1973], employs a further optimization of step-width and direction.

9 See WAGNER [1984b], [1986] for the idea of "Evolution der Evolutionsfähigkeit" the evolution of the possibility to generate evolution - in biology. What I term patterned variation here is closely related to ideas about "canalization" and "developmental constraints" in biology. Economists may find this congenial. The economist Kenneth BouLDING [1992, 183] asks whether "it is possible to have a genetic mutation that increases the rate of mutation." (The answer is yes.) Boulding relates this to the "extraordinary phenomenon of acceleration in social and economic systems, especially in the last few centuries." (p. 183). In another context, the economist Kaushik BASU [1996, 749] has argued that groups that never breed non-cooperating mutants may outcompete groups that do. 
This argument ties the nature of variation - its particular patterning - to the nature of the universe of organisms or organizations explored in the past. Empirically, this patterning shows up in the phenomenon of "morphological integration:" Variations in functionally interrelated traits are, as a rule, more strongly correlated than variations in functionally independent traits. ${ }^{10}$

In other words, if evolution starts in a blind way, the emerging evolutionary strategies will eventually be patterned according to their relative evolutionary success. Subsequent evolutionary processes must be conceived as patterned, even if evolution has started "originally" in a blind fashion. The argument does not necessarily imply that evolution was in fact "originally" blind. There is no necessity to argue about the nature of initial evolutionary processes. What matters are the later stages, where variation must be assumed to be patterned anyway. This certainly applies to humans and social institutions.

\section{Evolutionary Patterns in Biology}

Patterned variation will give rise to directed, rather than blind evolution, in the sense that changes are controlled by internal constraints. Such variation may be conceived as generating new forms of organisms as constructed according to certain rules and principles which govern variation. Successful trials are then selected by competition. In other words: Evolutionary developments create new possibilities and shape new constraints, thereby channeling further developments in particular ways. Here are some examples of evolutionary processes studied in biology, which may be understood as the outgrowth of patterned variation.

Channeling by Constraints. Patterned variation may be interpreted as variation within constraints. In biology, such "constraints" are conceived as "features of ontogenetic mechanisms and morphogenetic design which limit the power of selection to mold phenotypic traits." ${ }^{11}$ Constraints are sometimes structurally given. Gastropod shells can, for instance, assume only certain forms because of the way they grow. There cannot be gastropods with square shells. ${ }^{12}$ In this sense, developmental constraints limit the kinds of change that can occur - they pattern variation. Other constraints may arise at higher levels. Reptiles cannot accommodate to arctic climates, because their metabolism depends on external sources of heat. This constrains possible adaptations. Such phenomena may be envisaged as brought about by evolution working on jagged fitness landscapes, rather than being a direct consequence of physical constraints. The effect - the

10 WAGNER [1986, 136].

11 STEARNS [1982, 239].

12 The above follows Maynard Smith [1989, 142]. See also the discussion of constraints in WAGNER [1984b, 102]. The importance of constraints, in particular the laws of physics and chemistry, has been stressed by KöHLER [1960]. See also KUBON-GILKE [1996] for pertinent discussion. 
patterning of variation by genetic constraints - amounts to much the same as the patterning of the gastropod shells by structural or physical constraints.

Hitchhiking. Correlation of changes gives rise to the possibility that certain features emerge without any reason in terms of fitness. If two new traits $A$ and $B$ emerge conjointly, where trait $A$ improves fitness and trait $B$ is neutral or even slightly detrimental for fitness, trait $B$ may spread in a population because it is coupled with the successful trait $A$. Trait $B$ survives and spreads not because of its own fitness, but because it is hitchhiking with the successful trait $A$. It is, ultimately, the structural coupling of traits $A$ and $B$ which generates the effect. ${ }^{13}$

Radiation. Evolution is, in Darwin's classic phrase, "descent with modification." Newly emerging niches will, accordingly, be filled by new organisms which derive from existing organisms, rather than develop anew in an "optimally adapted" way. In this sense, history channels future possibilities. Marsupial evolution in Australia affords the classic example of such radiation. Marsupials occupy a wide variety of ecological niches in Australia and Tasmania. Some developments among them have coincidentally paralleled developments in placental mammalian evolution elsewhere, the Tasmanian wolf, for example, resembles placental wolves in the Northern hemisphere in many ways. ${ }^{14}$ Such phenomena of radiation illustrate how constraints emerge in biological evolution. Certain features, like a marsupium, once developed, create conditions and pose constraints for further developments; they pattern variation.

Founder Effects. Radiation and irreversibility work conjointly to produce "founder effects." New organisms will contain traces of older organisms. In particular, some crucial features present in the parent population may provide the starting point for further developments and canalize these developments in a particular and irreversible way, just as the marsupium is maintained by the diverse Australian marsupials, and no mammals have developed from them. ${ }^{15}$

Irreversibility. Consider an organism with different organs. All organs are subject to evolution. Further, each organ constitutes a part of the environment

13 WAGNER [1986, 140]. Note that the mechanism may also work in the reverse direction. A disadvantagous trait $B$ may block the spreading of an advantageous trait $A$, if both are coupled with each other.

A closely related effect is "feedback selection." An organism $A$ may outcompete another organism $B$ simply because it can accommodate faster to new circumstances, even if $B$ can achieve better fitness in a (properly defined) long-run sense.

14 EldREDGe [1989, 177].

15 The "founder effect" or "founder principle" in biology is usually phrased in a less extreme form by simply stating that the gene pool of an isolated population may differ from that of the parent population. This entails different selective conditions for the individuals in the peripheral group. Such differences may induce drastic genetic restructuring (MAYr [1982, 600-606]; ENCYClopaEdia BritanNiCA [1994, 902]). 
of the other organs. Thus, any change in one organ induces changes in the other organs, and further repercussions on the changing organ. Each adaptive step dismantles the conditions under which the other organs have developed and destroys, in this way, the bridges to the past. All organs will, therefore, exhibit traces of their history, but the route of return will be disbanded. ${ }^{16}$

Functional Shifts. One of the great problems in biology relates to the emergence of novelties. It has been asked, for example, how a rudimentary wing can be enlarged by natural selection before it enables its possessor to fly. One answer given by biologists is that the rudimentary wing may first evolve to serve some other function. Once it is large enough, it can be used as a wing. This induces a shift in function. In this way, the new feature builds on another, perhaps functionally unrelated, feature. ${ }^{17}$

Evolutionary Detours. Complex adaptations are envisaged as accruing through a series of intermediary stages. Such developments may not necessarily progress in a uni-directional way, but may entail various evolutionary detours. Functional shifts of various kinds may be required to bring about a complex matrix of new features. Each channel starts, so to speak, from previous channels, and there is no over-arching integrating force which enforces a coherent overall direction on the processes. Locations $A$ and $B$ may, so to speak, be situated fairly closely to each other, but evolution from $A$ to $B$ may involve a detour through a remote place $C .{ }^{18}$

Punctuation. It has been argued that variation is often patterned in such a way that jerky (or punctuational) rather than gradual evolution is generated. ${ }^{19}$ This punctualist thesis refers to a special case of patterning which may be important in both biology and the social sciences. According to these theories, blind evolution may play a role in locally optimizing a certain type of organism, but the evolutionary jumps involved in the development of new types of organisms are brought about by channeled changes, i.e. by patterned variation. ${ }^{20}$

${ }^{16}$ This paraphrases WAGNER [1984b, 108]. A formal proof is supplied in WAGNER [1982].

17 MAYR [1982, 610].

18 EldReDGe [1989, 210].

19 See EldREDGE and Gould [1972]; Gould [1977]; EldREDGe [1985], [1989].

20 The discussion regarding punctuational evolution remains unsettled in biology, in part because it ties back to the unexplored features of the underlying fitness landscapes, in part because the qualitative difference between "fast" and "slow" changes remains controversial. This discussion is reminiscent of the discussion around MARSHALL's [1890/ 1920] "long" and "short" periods, or PIAGET's [1967] "assimilation" and "accommodation." Note, however, that paleontologists have other time scales in mind, with "fast" punctuation taking place within 5,000 to 50,000 years, and "slow" stasis persisting for 5 to 10 million years (ELDREDGE [1989, 66 and 78]). 


\section{Evolutionary Patterning in Society}

Patterned processes in social evolution exhibit strong similarities to those occurring in biological evolution. The following remarks illustrate this parallelism.

Channeling by Constraints. Constraints are obviously of the utmost importance in social evolution. At any given point in time, society is swamped with customs and laws and characterized by an amalgam of knowledge and superstition. All this channels change by preventing certain developments while easing the way for others. In this way, the existing constraints, as brought about by evolution, channel future developments and structure the fate of society. ${ }^{21}$ Similar observations pertain to the evolution of organizations within society. Each single firm is characterized by a set of behavioral patterns, routines and convictions which ease cooperation while constraining and channeling change. ${ }^{22}$

Hitchhiking. Hitchhiking phenomena seem readily conceivable in the social sciences. Some inefficient aspects of the personal computer (such as the unnecessary "SysRq"-key) are spreading along with the item to which they are attached. Similarly, technical standards, languages, and habits may survive because they are coupled with competitively successful features, and changes in one feature of an organization may induce some slightly dysfunctional changes in somewhat unrelated dimensions. SCHUMPETER [1942] has argued, for instance, that capitalism will, by its very success, generate attitudes and preferences that undermine the moral foundations of market processes.

Radiation. There is, again, a strong case for radiation to be made in the social sciences. Many dissemination and diffusion processes may be envisaged as phenomena of radiation. The Western alphabet derives from Phoenician precursors, technologies or fashions spread, and some radically new inventions may be blocked by the presence of existing technologies which render it possible to solve new problems according to prevailing patterns.

Irreversibility. The argument about irreversibility can easily be applied to social processes. Newly emerging institutions will, for instance, entail changes throughout society, and thereby dismantle the conditions which gave birth to them. This entails irreversibility. The argument about irreversibility of evolutionary processes is obviously of immense importance for the social sciences. It sketches a way to go beyond the simple view that society selects its institutions

21 VANBERG [1996] has recently emphasized the importance of constraints for social evolution.

22 See SCHLICHT [1997, ch. 13]. 
by taking the best specimen from a pre-conceived book of blueprints, given the environmental conditons and the state of technology. ${ }^{23}$

Founder Effects. Founder effects can be observed on a large scale in many societies. The most prominent case in point is provided by the Hartz thesis according to which the societies of Australia, South Africa, Canada, or Latin America still carry the strong imprint of features of the parent societies prevailing at colonization. ${ }^{24}$ Similarly, many features of Western countries can be traced back to Roman or Celtic roots.

Functional Shifts. Again, we must take account of functional shifts in many dimensions of society. The origin of money has, for example, been traced back to religious practices. In other words, functionality has switched from the sacred to the profane. It would be illuminating to comb history texts from this perspective.

Evolutionary Detours. As in biology, we should expect (and seem to observe) evolutionary detours in social evolution. In a sense, a development going from democracy in Athens to modern democracy seems more straightforward than the actual course of history, involving the backlash of the Dark Ages. Likewise, it seems straightforward to conceive the modern firm as growing directly from the guild system, but the modern corporation has not developed in such a way. Rather, several other somewhat unrelated developments were required to bring about the modern corporation. The corporate ownership structure evolved in the sphere of trade and money, while the production arrangements were shaped by the development of the putting-out system and manufacture. Apparently there was no way to produce the adaptations - legal and otherwise - necessary for the development of the modern corporation by starting from the guild directly. Similarly, our modern alphabet has not been developed directly by associating certain elementary sounds with some elementary symbols, as behaviorists might have expected. Rather, the alphabetic characters have grown out of syllabic signs, and these developed from the pictorial representation of sound, which in turn derived from picture symbols denoting certain objects or ideas, quite unrelated to their pronunciation. Modern Japanese "kanjis" illustrate these earlier stages. In the European case, the invention of twenty-six symbols required a detour of several millennia, which is a considerable time span. ${ }^{25}$ It seems nearly impossible to account for such occurrences without resorting to patterned variation.

Punctuation. A discussion of punctuation in economics has hardly commenced though the idea of punctuation has a long and venerable history. ${ }^{26}$ While some

\footnotetext{
${ }^{23}$ NoRTH and ThOMas [1973].

24 HARTZ et al. [1964].

25 AsCH [1987, 109].

26 MOKYR [1990]; JONES [1995]; BOULDING [1992].
} 
economists (most notably Alfred Marshall [1890/1920]) have stressed the element of continuity and gradual progress, others (like Karl MARX [1873/ 1946]) have envisaged discontinuous revolutionary shifts in the overall character of society. Sometimes, these discussions carry a religious flavor, but this does not mean that the issue is settled in a theoretically compelling fashion. Modern arguments in system theory have pointed again to the possibility of both continuous and discontinuous change at the system level. ${ }^{27}$

\section{Psychology and Social Evolution}

In a formal way, the argument about patterned variation carries over to social processes: Without patterning, there would be no discernible evolution; once evolution begins, the processes of variation themselves are molded by evolutionary forces. If evolutionary processes are relevant on the level of society, they must be patterned.

The argument is, however, not entirely satisfactory, because basic traits of human nature have remained invariant throughout history. These features must be taken as givens for purposes of social analysis. As social processes emerge from the joint action of individuals, the patterning of individual behavior should not itself be considered as brought about by social evolution. Rather, the patterning of social evolution is engendered by the way individuals behave.

With regard to the behavior of individuals, however, the biological argument about patterning applies with full force in the sense that this behavior must indeed be assumed as patterned from the outset. The starting-point for social evolution is, then, provided by those patterned features of human behavior, thinking, and feeling, that remain unaffected by processes of social evolution. The theory of social evolution, unlike the theory of biological evolution, can start with these givens.

These givens comprise basic regularities of pattern recognition, routine formation and thinking, but also emotional and behavioral dispositions. Classical Gestalt psychology has focused on these fundamental aspects of human nature, and modern cognitive and social psychology continue this tradition. Theories about social evolution may benefit from using the knowledge accumulated in these fields. ${ }^{28}$

${ }^{27}$ Eger and WeISE [1993]; WeISE [1996, 719]. KURAN [1995, ch. 15-18] offers a theory of society-wide punctuation processes.

28. In SCHLICHT [1997], I have related various aspects of economic behavior, regarding custom, property, the law, the firm, and the market, to these psychological regularities. In a similar way, KUBON-GILKE [1997] has analyzed the (often implicit) psychological premises of institutional economics.

Incidentally, the rationality assumption used in economics may be interpreted as a device for generating behavioral patterns, in the sense that "rational" behavior can be distinguished from erratic behavior by obeying some constraints posed by rational calculation. 
The parallelism between biological and social patterning mentioned in the previous sections is supplemented by a number of similar features of learning processes. Without going too much into psychology, the following illustrates this correspondence.

Channeling by Constraints. People act on the basis of strategies, rules, or habits acquired in the past. This channels and constrains their future behavior. ${ }^{29}$

Hitchhiking. As people act from reasons and strategies, they treat "similar" cases similarly. This may entail maintaining dysfunctional aspects of otherwise functional behavior.

Irreversibility. People will develop new behaviors by means of old behaviors. If the old behaviors are forgotten, they cannot be reached again. Various stage theories of language learning illustrate such irreversibility.

Radiation. People learn by imitation, they use analogies and try to cope with new problems by applying established strategies and procedures.

Founder Effects. First impressions loom large and influence later developments strongly.

Functional Shifts. Many phenomena of insight are due to restructuring a given problem in an appropriate way.

Evolutionary Detours. Teaching practices, e.g., in musical education, rely heavily on certain detours.

Punctuation. Certain learning phenomena, especially those related to "insight learning," exhibit strong discontinuity. ${ }^{30}$

\footnotetext{
29 Recent theorizing about the role of "mental models" in institutional analysis starts from this observation (see NORTH and DENZAU [1994]).

${ }^{30}$ MAYNARD SMITH $[1989,149]$ challenges the punctionational position in remarking that "one does not know whether one is studying the rates of evolution of real organisms, or merely the habits of the taxonomists who gave the names to the fossils." Such a position suggests not that punctuation does not occur, but that it may arise not in the fossil records themselves but in the way people perceive the world. The fact that humans perceive the world in punctuational terms may be of even greater significance for the social sciences than "real" punctuation in the fossil record. ELDREDGE $[1989,134]$ has reversed Maynard Smith's argument when observing: "Many 'trends' singled out by evolutionary biologists are ex post facto renderings of phylogenetic history: biologists may simply pick out species at different points in geological time that seem to fit on some line of directional modification through time." This would, again, hint at the structuring force of human perception, albeit in another direction.
} 
What seems to be required, then, is a theory which derives the social patterning from the psychological patterning in a systematic way.

\section{Organic Growth}

Up to now, the discussion has focused on the nature of variation: Variation must be assumed patterned, rather than random. But variation is only one element in the process of evolution; the other is selection.

With regard to selection, biologists stress the importance of competition, and this element of competitive selection is undoubtedly of central importance not only in biology, but also in the analysis of social processes. ${ }^{31}$ Sometimes, however, competition is not an active selective force. Think about isolated societies on remote islands, or society-wide institutions like legal systems, kinship systems, or languages. ${ }^{32}$ For such institutions, the mechanism of external competitive selection may be absent. The evolution of such institutions must be conceived of as generated by patterned variation at the level of the elements of such systems, with changes brought about by the conditions prevailing in the system as a whole. Such systems, seen from the outside, will exhibit organic evolution and growth, i.e. patterned variation unchecked by any kind of selection. ${ }^{33}$ (Returning to the earlier example of mathematics, alternative approaches for solving certain problems within mathematics are selected by their success within mathematics.)

Further, patterned variation restrains certain alternatives from evolving, and variants may survive simply because no superior variants are generated by variation. Under such circumstances, competition cannot act as a selection device either. Change (or stasis) will be brought about by the interaction of internal factors alone.

\section{Constraints and Institutions}

In an abstract sense, any evolutionary argument can be described as follows: There is a set of feasible alternatives, and there is a selective mechanism which selects among the alternatives. The outcome of the selection process must depend, therefore, on the set of feasible alternatives, and on the mechanisms generating these feasible alternatives. The fact that humans have survived is due

\footnotetext{
31 The phrase "survival of the fittest" was actually invented by Spencer, not Darwin (see HallPIKE [1996, 682f.]).

32 Hallpike [1996].

33 As a matter of terminology, I use "organic growth" as "patterned variation without selection."
} 
to the fact that superior animals - with lesser needs but more power and more aggressiveness - have not emerged. Thus any explanation must rely on theories about what is not possible. ${ }^{34}$ In other words, it must rely on arguments about canalization and constraints. It must start from possible patterns. Thus, even within evolutionary arguments, a thorough knowledge of nature cannot be replaced by abstract principles. ${ }^{35}$ With regard to social analysis, this abstract argument may be supplemented by saying that the patterning of human behavior, which is a necessary prerequisite for the emergence of any kind of social structure, must originate in psychology, broadly conceived, and comprising not only cognition, but emotion and habit as well.

It has been said that "institutions are the humanly devised constraints that shape human interaction." ${ }^{36}$ I would prefer to put the emphasis differently. A categorical distinction between human design and social evolution seems problematic. In so far as institutions are "constraints that shape human interaction," these constraints are not brought about by human design alone, but are in part reflections of constraints working at the level of the individuals. The consistency requirements constraining a firm's compensation policies are, for example, not "humanly devised" but part and parcel of the way in which humans form perceptions of fairness. ${ }^{37}$ Human design starts from these givens. As purposeful behavior is patterned, not random, it generates patterned variation. The collective result of such activity is, however, not fully reducible to human design. Mechanisms of selection and interaction working at the level of society may generate quite unintended consequences. But the statement about institutions as humanly devised constraints is also biased in another way. Institutions are not merely constraints. Sometimes they create possibilities and shape motivations which would not otherwise be available.

\section{References}

Alchian, A. A. [1950], "Uncertainty, Evolution, and Economic Theory," Journal of Political Economy, 58(3), 211-221.

Asch, S. [1987], Social Psychology, 2nd ed., Oxford University Press: Oxford-New York-Tokyo.

BASU, K. [1996], "Notes on Evolution, Rationality, and Norms," Journal of Institutional and Theoretical Economics, 152(4), 739-750.

BouldiNG, K. E. [1992], "Punctuation in Societal Evolution," pp. 171-186 in: A. Somit and S. Peterson (eds.), The Dynamics of Evolution, Cornell University Press: IthacaLondon.

\footnotetext{
34 WITT [1987, 22].

35 Selten $[1991,9]$.

36 NORTH [1990, 3].

37 As another quite obvious instance, property is not a human invention (see SCHLICHT [1997, ch. 11]).
} 
CAMPBELl, D.T. [1974], "Evolutionary Epistemology," pp. 413-463 in: P. Schilpp (ed.), The Philosophy of Karl Popper, Vol. I, Open Court: Lasalle, IL.

EDEN, M. [1967], "Inadequacies of Neo-Darwinian Evolution as a Scientific Theory," pp. 5-19 in: P. Moorhead and M. Kaplan (eds.), Mathematical Challenges to the Neodarwinian Interpretation of Evolution, Symposium Monograph 5, Winstar International: Philadelphia.

Eger, T. and P. WeISE [1993], "Economic Transformation Processes: Political Possibilities and Social Limitations," pp. 51-65 in: H.-J. Wegener (ed.), On the Theory and Policy of Systemic Change, Physica: Heidelberg.

EldRedge, N. [1985], Time Frames: The Rethinking of Darwinian Evolution and the Theory of Punctuated Equilibria, Simon and Schuster: New York.

- [1989], Macro-Evolutionary Dynamics, McGraw-Hill: New York.

-- and S. J. Gould [1972], "Punctuated Equilibria: An Alternative to Phyletic Gradualism," pp. 82-115 in: T. J. M. Schopf (ed.), Models of Paleobiology, Freeman and Cooper: San Francisco. Reprinted in ELDREDGE [1985].

EnCyclopaedia BritanNiCa [1994], "Founder Principle," p. 902 in: The New' Encyclopaedia Britaninica, Vol. 4, 15th ed., Chicago.

Gould, S. J. [1977], Ontogeny and Phylogeny, Harvard University Press: Cambridge, MA.

HallPIKE, C. R. [1986], The Principles of Social Evolution, Clarendon: Oxford.

- [1996], "Social Evolution," Journal of Institutional and Theoretical Economics, 152(4), 682-689.

HarTZ, L. et al. [1964], The Founding of New Societies, Harcourt Brace Jovanovich: San Diego-New York-London.

Hayek, F. A. [1945], "The Use of Knowledge in Society," American Economic Review, $35(4), 519-530$.

Hodgson, G. M. [1996], "The Challenge of Evolutionary Economics," Journal of Institutional and Theoretical Economics, 152(4), 697-706.

JoNES, E. [1995], "Technology, the Human Niche and Darwinian Explanation," pp. 163 186 in: E. Jones and V. Reynolds (eds.), Survival and Religion. Biological Evolution and Cultural Change, John Wiley and Sons: Chichester-New York-Brisbane-Toronto-Singapore.

KÖHLER, W. [1960], "The Mind-Body Problem," pp. 3-23 in: S. Hook (ed.), Dimensions of Mind, New York University Press: New York. Reprinted in: M. Henle (ed.), 1971, The Selected Papers of Wolfgang Köhler, Liveright: New York, pp. 62-82.

KubON-GilkE, G. [1996], "Institutional Economics and the Evolutionary Metaphor," Journal of Institutional and Theoretical Economics, 152(4), 723-738.

-- [1997], Verhaltensbindung und die Evolution ökonomischer Institutionen, Metropolis: Marburg.

KüPPERS, B. O. [1983], “Zufall oder Planmäßigkeit. Erkenntnistheoretische Aspekte der biologischen Informationsverarbeitung," Biologie in unserer Zeit, 13(4), 109-119.

Kuran, T. [1995], Private Truths, Public Lies, Harvard University Press: CambridgeLondon.

LIsT, F. [1837], The Natural System of Political Economy, translated and edited by W. O. Henderson, Cass: London.

Marshall, A. [1890/1920], Principles of Economics, 8th ed., Macmillan: London.

MarX, K. [1873/1946], Capital, A Critical Analysis of Capitalist Production, Vol. 1, translated from the 3rd German ed. by S. Moore and E. Aveling and edited by F. Engels, with a supplement edited and translated by D. Torr, George Allen and Unwin: London.

MAYNARD SMITH, J. [1989], Did Darwin get it Right?, Chapman and Hall: New York-London.

MAYR, E. [1982], The Growth of Biological Thought, Harvard University Press: Cambridge, MA. 
MoKyr, J. [1990], The Lever of Riches, Oxford University Press: New York.

NORTH, D. [1990], Institutions, Institutional Change and Economic Performance, Cambridge University Press: Cambridge.

- - and A.T. DENZAU [1994], "Shared Mental Models: Ideologies and Institutions," Kyklos, 47(1), 3-31.

-- and R. P. Thomas [1973], The Rise of the Western World, Cambridge University Press: Cambridge.

Piaget, J. [1967], Biologie et Connaissance, Gallimard: Paris.

RECHENBERG, I. [1973], Evolutionsstrategie: Optimierung technischer Systeme nach Prinzipien der biologischen Evolution, Friedrich Frommann: Stuttgart-Bad Cannstadt.

SCHLICHT, E. [1997], On Custom in the Economy, Oxford University Press: Oxford.

SCHUMPETER, J. A. [1942], Capitalism, Socialism, and Democracy, Harper: New York.

SELTEN, R. [1991], "Evolution, Learning, and Economic Behavior," Games and Economic Behavior, 3, 3-24.

Stearns, S. C. [1982], "The Role of Development in the Evolution of Life Histories," pp. 237-258 in: J. T. Bonner (ed.), Evolution and Development, Springer: BerlinHeidelberg-New York.

VANBERG, V. [1996], "Institutional Evolution Within Constraints," Journal of Theoretical and Institutional Economics, 152(4), 690-696.

WAGNER, G. P. [1982], "The Logical Structure of Irreversible Systems Transformations: A Theorem Concerning Dollo's Law," Journal of Theoretical Biology, 96, 337-346.

- [1984a], "Coevolution of Functionally Constrained Characters: Prerequisites for Adaptive Versality," BioSystems, 17, 51-55.

- [1984b], "Über die populationsgenetischen Grundlagen einer Systemtheorie der Evolution," pp. 97-111 in: J. A. Ott, G. Wagner and F. Wuketits (eds.), Evolution, Ordnung und Erkenntnis, Paul Parey: Berlin-Hamburg.

-- [1986], "Evolution der Evolutionsfähigkeit," pp. 121-147 in: A. Dress, H. Hendrichs and G. Küpper (eds.), Selbstorganisation. Die Entstehung von Ordnung in Natur und Gesellschaft, Piper: München-Zürich.

WEISE, P. [1996], "Evolution and Self-Organization," Journal of Institutional and Theoretical Economics, 152(4), 716-722.

WITT, U. [1987], Individualistische Grundlagen der evolutorischen Ökonomik, Mohr Siebeck: Tübingen.

- [1996], "A 'Darwinian Revolution' in Economics?" Journal of Institutional and Theoretical Economics, 152(4), 707-715.

Professor Ekkehart Schlicht

Seminar für Theorie und Politik der Einkommensverteilung

Fakultät für Volkswirtschaftslehre

Ludwig-Maximilians-Universität München

Schackstraße 4

80539 München

Germany 